ISSN 2525-3409 | DOI: http://dx.doi.org/10.33448/rsd-v8i8.1035

\title{
Boas práticas na Educação a Distância e o sucesso em uma turma de Pedagogia
}

Buenas prácticas en la Educación a Distancia y el éxito en una clase de Pedagogía Good practices in Distance Education and success in a Pedagogy class

Recebido: 08/03/2019 | Revisado: 16/03/2019 | Aceito: 25/05/2019 | Publicado: 30/05/2019

\section{Ricardo Shitsuka}

ORCID: http://orcid.org/0000-0003-2630-1541

Universidade Federal de Itajubá, Brasil

E-mail: ricardoshitsuka@unifei.edu.br

Dorlivete Moreira Shitsuka

ORCID: http://orcid.org/0000-0002-3282-4843

Grupo de Pesquisas MEAC, Brasil

E-mail: dorlivetems@gmail.com

Maria Fani Scheibel

ORCID: https://orcid.org/0000-0002-5381-4791

Grupo de Pesquisas MEAC, Brasil

E-mail: mfani@terra.com.br

Alaíde Japecanga Pereira

ORCID: http://orcid.org/0000-0003-2095-615X

Universidade do Estado de Mato Grosso, Brasil

E-mail: japecanga@uems.br

\section{Caleb David Willy Moreira Shitsuka}

ORCID: https://orcid.org/0000-0002-9813-0457

Universidade Brasil, Brasil

E-mail: cashitsuka@gmail.com

Max Leandro de Araújo Brito

ORCID: http://orcid.org/0000-0002-3282-4843

Universidade Federal do Rio Grande do Norte, Brasil

E-mail: maxlabrito@gmail.com

\section{Resumo}

Atualmente a Educação a Distância (EAD) continua se expandindo na Educação Superior brasileira. Uma medida recente do Ministério da Educação ampliou a possibilidade de 
aumentar de $20 \%$ para $40 \%$ a possibilidade de disciplinas a distância em cursos presenciais, desde que as instituições e cursos respeitem as normas legais. A educação a distância é uma modalidade educacional na qual nem todos os alunos se adaptam uma vez que ela pressupõe a autonomia do aluno na busca e construção do saber, mediante o material didático e a metodologia das disciplinas em promover a participação do aluno nas atividades propostas. A questão que se coloca é se há formas de superar as dificuldades desta modalidade? O objetivo do presente estudo é apresentar um estudo de pesquisa-ação em grupos de alunas de uma disciplina a distância de um curso de Pedagogia na qual inicialmente ocorrem dificuldades com relação à EAD. Realiza-se um trabalho de pesquisa-ação o qual se inicia por meio da verificação da existência de dificuldades de aprendizado detectada pela Comissão Própria de Avaliação nas alunas do curso. Faz-se então um trabalho colaborativo que resulta em alteração na forma de trabalho na EAD com a adoção de boas práticas. Verifica-se que os alunos melhoram seu desempenho escolar mostrando que há casos em que é possível melhorar a aprendizagem e satisfação dos estudantes nesta modalidade..

Palavras-chave: Educação Superior; Disciplinas a distância; Comissão Própria de Avaliação; Pesquisa-ação.

\begin{abstract}
Distance Education (EAD) continues to expand in Brazilian Higher Education. A recent measure by the Ministry of Education has increased the possibility of increasing distance learning courses from $20 \%$ to $40 \%$ in face-to-face courses, provided that institutions and courses comply with legal standards. The distance education is an educational modality in which not all the students adapt since it presupposes the student's autonomy in the search and construction of the knowledge, through didactic material and the methodology of the disciplines in promoting the participation of the student in the proposed activities. The question is whether there are ways to overcome the difficulties of this modality? The objective of the present study is to present a study in a distance discipline in which difficulties initially occur in the educational process and these are worked through good practices. A work of research-action is carried out in a discipline of scientific methodology of a Pedagogy course in the southeast region in which the implementation of $20 \%$ of EAD was initiated. Initially it is detected the existence of learning difficulties detected by the Evaluation Committee of the students of the course. There is a collaborative work that results in a change in the way of work. It is verified that the students improve their school performance showing that there are cases in which it is possible to improve the learning and satisfaction of the students in this modality.Keywords: Higher Education; Distance Disciplines; Own Evaluation Committee; Action research.
\end{abstract}




\section{Resumen}

Actualmente la Educación a Distancia (EAD) continúa expandiéndose en la Educación Superior brasileña. Una medida reciente del Ministerio de Educación amplió la posibilidad de aumentar del $20 \%$ al $40 \%$ la posibilidad de disciplinas a distancia en cursos presenciales, siempre que las instituciones y cursos respeten las normas legales. La educación a distancia es una modalidad educativa en la que no todos los alumnos se adaptan una vez que ella presupone la autonomía del alumno en la búsqueda y construcción del saber, mediante el material didáctico y la metodología de las disciplinas en promover la participación del alumno en las actividades propuestas . La cuestión que se plantea es si hay formas de superar las dificultades de esta modalidad? El objetivo del presente estudio es presentar un estudio en una disciplina a distancia en la cual inicialmente ocurren dificultades en el proceso educativo y, éstas son trabajadas por medio de buenas prácticas. Se realiza un trabajo de investigación-acción un trabajo en una disciplina de metodología científica de un curso de Pedagogía presencial en la región sudeste en el cual se iniciaba la implantación del 20\% de EAD. Inicialmente se detecta la existencia de dificultades de aprendizaje detectada por la Comisión Propia de Evaluación en las alumnas del curso. Se hace entonces un trabajo colaborativo que resulta en alteración en la forma de trabajo. Se verifica que los alumnos mejoran su desempeño escolar mostrando que hay casos en que es posible mejorar el aprendizaje y satisfacción de los estudiantes en esta modalidad.

Palabras clave: Educación Superior; Disciplinas a distancia; Comisión Propia de Evaluación; La investigación-acción.

\section{Introdução.}

A Educação a Distância (EAD) é uma modalidade educacional desafiante. Ela combina a possibilidade de desenvolver o conteúdo e o saber dos estudantes, com a possibilidade de estudar em locais distantes, com horários flexíveis e como considera Vergara (2007), com autodidatismo. Este aspecto ocorre quando o aluno estuda isoladamente com seu material didático.

A EAD pode ocorrer, em cursos superiores presenciais no Brasil por meio de disciplinas ou partes de disciplinas. Muitos cursos presenciais têm trabalhado com até $20 \%$ de disciplinas a distância e a legislação recente, como considera Brasil (2018) permite até 40\% de modo a aumentar o conteúdo EAD e possibilitar que muitos cursos se tornem semipresenciais.

Nem todos os alunos se adaptam a modalidade a distância, que exige pesquisa e busca do saber de modo ativo, não bastando ficar sentado em uma cadeira aguardando de modo 
passivo, o professor transmitir a matéria e resolver os exercícios. Na EAD, nem sempre as instituições contam com a experiência na modalidade e, isso pode resultar em dificuldades de aprendizado e reclamações por parte dos alunos e, como consideram Boghi, Shitsuka \& Shitsuka (2019), pode levar à evasão escolar.

Os autores do parágrafo anterior, estudaram as dificuldades de alunos com problemas de depressão que os levava a apresentar dificuldades nos estudos na modalidade a distância. Neste estudo, o curso é presencial com alguma disciplina a distância porém considera-se válidas algumas formas de lidar com as dificuldades dos estudantes, uma vez que elas proporcionaram uma melhoria na aprendizagem e diminuição da evasão escolar.

Verifica-se na literatura que existem práticas que podem ajudar a melhorar o trabalho das instituições e professores com relação aos alunos de cursos a distância. Uma prática interessante para melhorar a realidade do aluno das Instituições de Ensino Superior (IES), uma vez que está presente nas instituições é aquela que recomenda que os alunos façam suas reclamações por meio da Comissão Própria da Avaliação (CPA). Conforme Brasil (2004), a avaliação institucional por meio da CPA foi instituída para todos cursos superiores incluindo os presenciais e aqueles à distância. Consideramos então, que essa pode se constituir em uma fonte de informações sobre as dificuldades dos alunos e pode fornecer o feedback necessário para melhorar a educação e suas condições como um todo.

Como consideram Carvalho, Oliveira \& Lima (2018, p. 224) a CPA faz a avaliação institucional que possibilita o "autoconhecimento da IES quanto às ações que desenvolve em torno do ensino, da pesquisa e da extensão". A CPA deve realizar levantamentos periódicos por meio de questionários aos atores da faculdade, divididos em seus segmentos: alunos, professores, funcionários e chefias.

O objetivo deste artigo é apresentar um estudo no qual os alunos de um curso de Licenciatura presencial, localizado na região Sudeste, que em um momento inicial apresentam dificuldades de aprendizagem em disciplinas a distância em uma instituição que estava se iniciando nos $20 \%$ para começar a adquirir o expertise nesta modalidade.

O ensino de disciplinas a distância conta com as salas de aula virtuais ou Ambientes Virtuais de Aprendizagem (AVA). Estes contêm ferramentas para a interatividade entre alunos e professores ou tutores. Entre as ferramentas existem portfólios, atividades textuais, fóruns, chats, wikis, glossários, vídeos, cafés virtuais e outras. Nem sempre as ferramentas são bem utilizadas por desconhecimento ou falta de experiência na modalidade.

Nas linhas seguintes aborda-se a questão da porcentagem de disciplinas a distâncias permitidas pela Lei e que está em evolução. Após este item trabalha-se a questão das boas 
práticas na EAD. O passo seguinte apresenta metodologia da pesquisa-ação participativa que foi empregada para a busca de soluções para problemas no ambiente educacional. Após a metodologia apresenta-se o estudo com suas discussões e as considerações finais.

\section{Até $40 \%$ de Disciplinas a Distância nos cursos Presenciais.}

Uma das áreas de saber ou atuação humanas que apresenta suas particularidades é a da Educação a Distância. Nesta, é preciso ter a infraestrutura, recursos e pessoal preparado para lidar com os processos de ensino e de aprendizagem. No Brasil a EAD se iniciou há muitas décadas por meio de cursos por correspondência do Instituto Monitor no final da década de 30 do século anterior como considera Zamlutti (2006). Na década de 70 foram desenvolvidos cursos por TV pela Fundação Cultura em conjunto com a Fundação Roberto Marinho e, posteriormente, por meio da Internet e Web, houve o desenvolvimento de cursos com emprego de recursos das Tecnologias Digitais de Informação e Comunicação (TDIC).

Ao longo das décadas de EAD no Brasil houve o desenvolvimento de um "expertise" por meio de estratégias e formas de trabalho que se mostraram mais bem sucedidas e em 2016 por meio da Portaria n. 1134 regulamentou-se a possibilidade de realizar até $20 \%$ de disciplinas a distância (Brasil, 2016). Observa-se que os $20 \%$ podem estar distribuídos em algumas disciplinas ministradas a distância ou então, em disciplinas presenciais com alguma como parte ou porcentagem realizada a distância. Para que isso ocorra, a legislação mencionada exige que a Instituição possua pelo menos algum curso de graduação já reconhecido, é necessário que as disciplinas ou a parte EAD constem no Projeto Pedagógico do Curso (PPC). Também se exige que as disciplinas a distância tenham avaliações presenciais e, é preciso que no PPC do curso sejam explicitados os métodos e práticas de ensino e aprendizagem que incorporem o emprego das Tecnologias de Informação e Comunicação (TIC) ou seja, contando com a infraestrutura física e os recursos multidisciplinares de tutores, professores e metodologias para que o sistema funcione bem nos processos educacionais.

No final de 2018, houve um aumento da porcentagem possível de ser realizada a distância em cursos presenciais para até $40 \%$. Segundo a Portaria n. 1.428, de 28 de dezembro de 2018 que está apoiada na Portaria Normativa MEC no 315, de 4 de abril de 2018 a Instituição já deve estar credenciada para a oferta de Educação a Distância, os índices de qualidade como é o caso do Conceito Institucional (CI) e do Conceito de Curso devem ser maiores ou iguais a 4 (quatro) e também a instituição não pode estar submetida a processo de 
supervisão (Brasil, 2018).

Observa-se que a possibilidade de chegar até $40 \%$ de disciplinas a distância em cursos presenciais faz com que os cursos tendam cada vez mais a trabalhar de modo misto. Para Mirshawka \& Mirshawka (2002) os cursos superiores tenderiam a alcançar uma modalidade que é intermediaria entre a presencial e a distância que é denominada em inglês de blended learning. Tal trabalho educacional misto envolve uma parte presencial e outra a distância e desta forma, consideramos que estes autores já enxergavam há mais de uma década e meia o que aconteceria anos após. Desta forma, considera-se importante que haja pessoas que enxerguem as tendências e disseminam o saber na sociedade.

Ainda de acordo com a legislação (Ibid, 2018), o limite de 40\% EAD não se aplica a cursos de graduação presenciais da área de saúde e das engenharias. Observa-se que alguns cursos como é o caso de Psicologia e Medicina ainda não contam com cursos EAD em nosso País.

\section{Boas práticas na EaD para os alunos, tutores e disciplinas.}

O bom senso das pessoas de uma determinada área de atuação ou saber aponta para formas de trabalho que estão fornecendo resultados positivos e utilizáveis para melhorar a qualidade, produtividade ou minimizar custos ou como forma de se aumentar as possibilidades de se alcançar os objetivos propostos na área em foco.

As boas práticas são formas de trabalhar que têm reconhecimento pelo mercado e pela sociedade ou parte da sociedade que está envolvida com o problema ou condição a ser focada. Elas não são exclusivas da Educação a Distância ou de alguma área de saber específica: cada área de atuação ou saber pode ter um conjunto de boas práticas que vão favorecer o sucesso.

Boas práticas metodologias ou formas trabalho que estão fornecendo bons resultados em algum setor da sociedade, área do saber ou algum grupo social, em determinado período e sob determinadas condições.

No caso da Educação a Distância, torna-se necessário que existam os recursos e que sejam trabalhadas as questões do saber e fazer docentes tanto no viés do ensino quanto no da aprendizagem para que os processos educacionais ocorram da forma melhor possível.

Para Teixeira et al (2017) o comentário rápido das postagens dos alunos é uma forma de fazer com que eles não se sintam solitários no AVA. A fixação de um período limite para o tutor realizar comentários das postagens dos alunos pode favorecer a melhoria do relacionamento entre os atores do curso além de se constituir em um item de melhoria da 
qualidade do curso.

Biagiotti (2005) apresenta a aplicação de rubricas na EAD mostrando que elas as rubricas são ferramentas úteis para a avaliação de processos e produtos finais na educação. Consideramos que o emprego de rubricas facilita o trabalho de correção de exercícios de modo a favorecer o feedback do aprendizado aos alunos na EAD.

Basso (2017) adota como boa prática o emprego de rubricas. Estes, no caso exemplificado pelo autor, são constituídos por tabelas de critérios associadas a escala Likert para avaliar exercícios de matemática em turmas do ensino médio. Apesar de não se tratar de ensino superior, nem de EAD, torna-se interessante observar como o uso de rubricas pode apoiar os processos educacionais em qualquer nível inclusive a Educação a Distância em nível superior e desta forma são úteis para que os tutores não gastem muito tempo nas avaliações de trabalhos e além disso, podem tornar mais claros e transparentes para os alunos, os critérios de avaliação.

Entre outras boas práticas na EAD, há o emprego da afetividade nas relações de interatividade entre tutores e alunos. Em um estudo realizado por Silva, Shitsuka \& Paschoal (2014) no qual se trabalha o ensino a distância de línguas, os autores consideram que a afetividade se constitui em um fatores de sucesso em cursos EAD. De fato a afetividade, pode ser manifestar por meio da dialogia, quando existe a boa comunicação entre os atores envolvidos no processo educacional.

Para Tenório, Costa \& Tenório (2016) a empatia do tutor que é a capacidade dele se colocar na situação do aluno durante a realização dos cursos, pode ajudar a melhorar a participação dos atores e a aprendizagem. Quando existe a empatia, também há o entendimento entre os envolvidos que passam a se engajar melhor no processo educacional em curso de modo a se constituir em uma boa prática para esta área de atuação e desta forma, pode-se considerar que a empatia do tutor é uma boa prática educacional para a EAD.

Shitsuka \& Shitsuka (2018) consideram que o emprego de recursos entre os quais o uso de vídeos e os encontros presenciais são formas de melhorar os processos educacionais na EAD. Consideramos que o emprego de mídias e atividades diversas e variadas favorece o envolvimento dos estudantes e o aprendizado em cursos à distância.

No caso dos alunos, ainda para Ibidem (2018) torna-se necessário que eles aprendam a se organizar e entre os recursos para que isso ocorra estão: 1) o emprego de mapas conceituais que ajuda os alunos a organizar suas mentes e o saber já possuído sobre algum tema; 2) o uso de cronogramas nos quais estão assinaladas as datas de entrega ou os períodos de participação nas atividades, bem como as datas das avaliações das diversas disciplinas que estão em curso 
no semestre e, 3) O trabalho colaborativos com os colegas em ferramentas como é o caso do fórum ou mesmo de correio eletrônico, dialogando e buscando entendimento sobre os assuntos em estudo e a forma de lidar com as dificuldades.

Consideramos que estes itens anteriores se constituem em boas práticas para a modalidade em foco e desta forma, acreditamos que o emprego das boas práticas favorece o aprendizado, o engajamento e, o sucesso dos alunos nos estudos, e por conseguinte à satisfação dos estudantes e da minimização da evasão escolar na EAD.

\section{Metodologia.}

Uma metodologia é um caminho ou conjunto de passos para se alcançar algum objetivo. A metodologia científica é utilizada na Academia ou nas escolas com a finalidade de realização de trabalhos que tenham embasamento cientifico em especial na educação superior, como considera Severino (2016), torna-se interessante o trabalho conjunto entre ensino, pesquisa e extensão.

Uma das formas de se realizar pesquisas nos ambientes de trabalho é por meio da pesquisa-ação participativa como considera Thiollent (2011). Por meio deste tipo de estudo, torna-se possível a busca por soluções para os problemas que surgem no ambiente profissional. Entre esses ambientes, as escolas são locais interessantes para o emprego dessa metodologia como preconizam Ludke \& Andre (2013) uma vez que nela existem processos educacionais e pessoas envolvidas e na medida que surgem as dificuldades, torna-se interessante buscar soluções conjuntas e participativas.

Pereira, Shitsuka, Parreira \& Shitsuka (2018) quando estudam a questão metodológica na elaboração de trabalhos científicos também vão ao encontro das colocações realizadas pelos autores mencionados e consideram a pesquisa-ação participativa aplicável em ambientes escolares como é o caso da EAD e suas salas de aula virtuais.

Realiza-se um trabalho de pesquisa-ação em uma disciplina de metodologia cientifica de um curso de Pedagogia presencial no qual se iniciava a implantação de $20 \%$ de EAD. Sendo o primeiro curso da Instituição de Ensino Superior (IES) localizada no interior na região sudeste a trabalhar com uma disciplina a distância, em 2017 e, sendo uma instituição de pequeno porte, não havia um expertise na IES relacionado com este tipo de educação. Inicialmente os alunos estranharam o fato da disciplina ser oferecida da distância que foi uma medida da Administração da Faculdade que foi tomada no período das férias escolares. 
Sendo a coordenadora do curso, nova e inexperiente, bem como o corpo docente, também formado, na grande maioria, por professores especialistas que não possuíam o conhecimento em relação à Educação a Distância estes apresentavam dificuldades em realizar propostas de melhoria. A ideia da Administração na época era no sentido de que os professores colocassem apostilas no site da IES. Como exemplo, o professor da disciplina "Metodologia Cientifica" deveria elaborar e inserir apostilas de sua disciplina de modo que os alunos acessassem este recurso, lessem e viessem fazer as provas nas datas agendadas sem mais nenhum tipo de suporte ou interatividade.

Houve a disponibilização do material didático no website da IES porém não havia um Ambiente Virtual de Aprendizagem nem uma metodologia claramente definida e nesta situação, os alunos mostram-se perdidos em relação a disciplina e surgiram as reclamações que se manifestaram nos levantamentos e respectivos relatórios da Comissão Própria de Avaliação (CPA) da IES. Esta comissão é composta por membros da instituição: professor, alunos, e membros da sociedade civil e sua missão é realizar um levantamento periódico das condições de oferta, condições de ensino e satisfação dos atores atuantes na faculdade em relação aos recursos disponibilizados.

A coordenação do curso verificou por meio do relatório periódico da CPA que havia muita reclamação em relação a disciplina Metodologia Científica e agendou uma reunião com as alunas do curso de Pedagogia e também de outros cursos para saber o que estava acontecendo e o que poderia ser feito para mudar a situação. A grande maioria dos alunos, cerca de $85 \%$, mostrou-se insatisfeita com a forma de trabalhar da disciplina EAD. Muitos afirmaram que era necessário que a IES instalasse e disponibilizasse um Ambiente Virtual de Aprendizagem (AVA) ou seja, uma sala de aula virtual e que nela houvesse ferramentas de interatividade para que os alunos pudessem interagir, tirar dúvidas em relação a disciplina.

Foram tomadas declarações de alunos em turmas do ano de 2018 e, apresentam-se amostras anteriores e posteriores ao emprego das boas práticas. Realiza-se o estudo dos enunciados por meio da Análise do Discurso segundo a Escola Francesa considerando-se Pecheux (2011) que faz uso do contexto para entender um enunciado. Este tipo de análise é qualitativa e nos ajuda a entender o sentido da fenomenologia.

Em respeito ao pedido dos atores participantes do estudo e às questões éticas, evitouse citar localidades e nomes dos envolvidos.

\section{Resultados e Discussão.}


No primeiro semestre de 2018, em uma faculdade presencial localizada na região Sudeste que possuía cursos reconhecidos pelo MEC, houve a introdução de até $20 \%$ de disciplinas a distância. Como inicialmente não a EAD não era parte da cultura institucional que estava se iniciando nesta área de saber, a direção convidou alguns professores dos cursos e algumas disciplinas para que este preparassem um material didático o qual seria disponibilizado aos alunos no website bem como agendassem datas de avaliações presenciais e desta forma seria "inaugurado" o EAD nesta IES.

A turma de 2018.1 era formada inicialmente por 45 alunas e no final do semestre ficou com 39. Já a turma ingressante em 2018.2 contou inicialmente com 35 alunas e no final do semestre não houve evasão.

Por meio dos dados coletados pela CPA, detectou-se a insatisfação das alunas com a EAD da faculdade. Nos levantamentos realizados, verificou-se que a grande maioria das alunas entrevistadas considerou que as disciplinas EAD em complicadas e difíceis de estudar. Muitas destas disciplinas não haviam sido cursadas anteriormente, ou seja, era a primeira vez que estavam estudando nelas, mas as alunas já possuíam algumas referências por parte das colegas de turmas mais avançadas.

A dificuldade verificada foi repassada para a direção que chamou os coordenadores e solicitou que se realizassem um trabalho de pesquisa-ação em conjunto entre alunos, professores, coordenação e direção da faculdade que teve como consequência a adoção de boas práticas na EAD.

As boas práticas na EAD se iniciaram com a definição de que haveria a utilização do AVA Moodle com as ferramentas de interatividade. Nesta ocorreria a participação ativa dos professores tutores chamando os alunos à participação na sala de aula virtual, o emprego de rubricas, a orientação inicial para organização dos alunos para acompanhar as disciplinas e os tutores deveriam ser capacitados e receber uma remuneração por horas trabalhadas no ambiente virtual. Algumas declarações tomadas de alunos antes da realização dos trabalhos mencionados foram.

Apresenta-se a seguir algumas declarações de estudantes da disciplina em duas situações: num primeiro momento apresenta-se as amostras de dados coletados antes do emprego das boas práticas quando haviam as reclamações registradas e, no segundo 
momento, apresentam-se declarações de alunas da turma seguinte que já se iniciou com as novas práticas de EAD da IES para a disciplina.

Como consideram Boghi, Shitsuka \& Shitsuka (2019) muitos alunos ao não acompanhar os cursos acabem desistindo. Observa-se a declaração da aluna 1:

Alguns colegas já desistiram do curso por não conseguir acompanhar as disciplinas EAD. O pessoal do Centro Acadêmico falou para reclamarmos na avaliação da CPA.

A declaração revela um lado importante na EAD que é a questão da evasão escolar como mencionado pelos autores Ibidem (2019). A evasão é causada principalmente porque o aluno não sente que está aprendendo e que pode ser bem-sucedido nas disciplinas, no curso e por conseguinte na nova carreira e na vida profissional. Torna-se interessante que haja algum mecanismo a faculdade verifique o que está acontecendo na disciplina e, considera Carvalho, Oliveira \& Lima (2018) um destes mecanismos é a CPA da faculdade e por meio dela como cita a aluna, torna-se possível explicitar a insatisfação em relação à forma como a disciplina está sendo trabalhada no semestre.

Pessoas são seres sociais e sentem a falta da comunicação hunana. Silva, Shitsuka \& Paschoal (2014) consideram que a comunicação ou seja, a afetividade pode atuar como incentivador da aprendizagem, satisfação e continuação em um curso EAD. Teixeira et al (2017) o comentário rápido das postagens dos alunos é uma forma de fazer com que eles não se sintam solitários no AVA. Quando a matéria é colocada nos websites sem que haja interação que servirá de incentivo para que os alunos possam estudar e se motivar a adquirir mais saberes, a aprendizagem se torna empobrecida. Como consequência o aluno vai desistindo de estudar. Pode-se observar a situação mencionada na declaração, amostra, da aluna 2:

Não é má vontade dos alunos. Acontece que as matéria de Metodologia Científica é "jogada" no site da faculdade e, a gente fica perdida sem saber o que estudar, o que vai ser pedido nas provas e 
Res., Soc. Dev. 2019; 8(8):e01881035

ISSN 2525-3409 | DOI: http://dx.doi.org/10.33448/rsd-v8i8.1035

como estudar. Aí vem o dia da prova e a maioria que não colou, reprova.

Verifica-se que a aluna tem um senso crítico que já lhe permite identificar algumas dificuldades que estão ocorrendo na disciplina. E a necessidade da faculdade cumprir a legislação como considera Brasil (2016) que mesmo para oferta de $20 \%$ EAD torna-se necessário que a instituição conte com uma infraestrutura tecnológica para disponibilização e interatitividade nas disciplinas EAD bem como é preciso contar com uma estrutura multidisciplinar de pessoal para que as disciplinas a distância possam funcionar dentro das condições legais.

Após a identificação de dificuldades pela CPA e a realização do trabalho de pesquisaação que resultou em melhorias no final do semestre com a introdução do AVA e o início do trabalho tutoral e, no semestre seguinte, fez-se um novo levantamento de dados dos alunos por meio de entrevistas e apresenta-se algumas declarações de alunos aferidas no início do semestre seguinte. A seguir, apresenta-se a declaração da aluna 3, que é coletada no final do semestre, após a implantação das mudanças e a utilização dos novos recursos e das boas práticas.

Os colegas estão adorando as disciplinas EAD. Os tutores são atenciosos e sempre estão disponíveis para nos atender e comentar em no máximo 24 horas, alguma postagem que algum aluno fez.

Verifica-se que está ocorrendo uma "sintonia" ou uma comunicação eficiente uma vez que ela está favorecendo o cumprimento dos objetivos educacionais. Os tutores "atenciosos" estão trabalhando como considera Silva, Shitsuka e Paschoal (2014) com afetividade uma vez que está havendo comunicação, comentários a todas postagens e como considera Tenório, Costa e Tenório (2016) a condição sócio afetiva pode levar a um melhor aprendizado. Como consequência dos fatos mencionados, os estudantes mostram-se satisfeitos e felizes e diminuise a evasão escolar. Alunos com mais motivação podem organizar melhor seus horários de estudo e interagir com os colegas, tutoria e curso que são fatores para um melhor desempenho 
como consideram Shitsuka e Shitsuka (2018). A seguir verifica-se esta condição por meio da declaração, amostra, da aluna 4:

Agora os alunos conversam uns com os outros nos fóruns e chats e as atividades são corrigidas pelos professores tutores com rapidez e todo sistema está funcionando bem.

Uma das maiores dificuldades da EAD é a separação física entre os alunos. Esta separação pode ser minimizada por meio do emprego dos recursos de Tecnologias Digitais de Informação e Comunicação (TDIC). Como considera Brasil (2016), para que uma instituição de ensino superior faça o uso dos $20 \%$ de EAD nos cursos presenciais é necessário que disponibilize os recursos de infraestrutura de tecnologia que incluem os fóruns e chats mencionados bem como os professores e tutores os quais devem estar trabalhando segundo as boas práticas existentes. Tudo leva crer que esta forma de atuação leva a melhores resultados na EAD que como consideram Shitsuka, Shitsuka (2018) e também Risemberg, Shitsuka e Tavares (2015) é uma modalidade cuja qualidade dos resultados depende da qualidade da participação dos atores e, se "tudo está funcionando bem" é o sentido da qualidade observada pela aluna que pode ser considerada como cliente dos serviços educacionais. A qualidade da participação também envolve a questão da empatia que um tutor tem que ter em relação aos alunos durante sua participação nos ambientes virtuais. Tenório, Costa e Tenório (2016) consideram essa questão da empatia como sendo uma qualidade fundamental para o tutor EAD e como consequência pode-se diminuir a insatisfação e a evasão. Observa-se esta situação na declaração da aluna 5:

Nenhuma aluna desistiu do curso após as melhorias que foram feitas nas disciplinas EAD e muitas dizem que estas estão melhores que várias disciplinas presenciais.

Verifica-se por meio das declarações que quando uma disciplina EAD em um curso presencial, trabalha com as boas práticas, o aprendizado pode ocorrer de modo facilitado. 
Desta forma, pode-se entender a questão diminuição da evasão que como menciona Boghi, Shitsuka e Shitsuka (2018) é uma agravante na modalidade a distância. Também pode-se inferir que a satisfação das alunas as leva a crer que a modalidade a distância apresenta vantagens em relação â presencial e que desta forma, confirma-se o que Mirshawka e Mirshawka (2002) consideram como sendo uma tendência para o ensino presencial, este ir fazendo o emprego de recursos da EAD de modo a alcançarmos uma porcentagem de EAD. Este fato também vai ao encontro de Brasil (2016) que considera o emprego dos 20\% EAD em cursos superiores e Brasil (2018) que chega aos $40 \%$ de emprego desta modalidade em cursos presenciais.

Com o aumento da quantidade possível de porcentagem de EAD nos cursos presenciais, novas situações e dificuldades podem surgir. Uma das melhores formas de se trabalhar as dificuldades organizacionais, como considera Thiollent (2011) para as organizações em geral e Ludke \& Andre (2013) e Pereira, Shitsuka, Parreira \& Shitsuka (2018) para as escolas de todos os níveis, a pesquisa-ação participativa pode ser a melhor forma de se envolver as pessoas na busca da resolução de problemas comuns e que pode gerar um saber comum que pode levar as IES para novos níveis mais elevados de qualidade e por conseguinte de satisfação dos seus atores.

A declaração seguinte, da professora tutora vai ao encontro desta situação:

Antes do trabalho de pesquisa-ação não havia tutoria de fato. Com a faculdade investindo em infraestrutura e contratação de profissionais preparados para realizar um trabalho com o emprego das boas práticas acredito que tenhamos um presente e futuro melhor nos cursos da faculdade.

Como considera Thiollent (2011), a pesquisa-ação é uma forma de resolução de problemas que envolve os atores participantes do processo em curso. Consideramos que esta metodologia de pesquisa e resolução de problemas é bastante útil nas empresas e na sociedade uma vez que coloca frente-a-frente as partes envolvidas e o problema e busca-se soluções colaborativas que atendam as partes envolvidos e que portanto tem maior possibilidade de 
contar com o engajamento de todos. Sem este engajamento, qualquer solução poderia não ser efetiva. Em particular, nos problemas educacionais envolvem-se recursos e pessoas.

Segundo Ludke e Andre (2013) e Pereira et al. (2018), estes ambientes são propícios ao emprego da pesquisa-ação. De fato, na escola, encontram-se alunos, professores, tutores, coordenadores, funcionários administrativos, bibliotecários e outros de modo que quando surgem problemas que afetem os processos educacionais ou a satisfação dos envolvidos, pode-se buscar soluções conjuntas que vão no sentido das boas práticas e que promovam o engajamento de todos na busca de soluções comuns que atendem da melhor forma possível aos segmentos presentes neste ambiente.

Verifica-se também que houve um aspecto importante que foi o levantamento do problema que foi detectado pela CPA da IES. Como consideram Carvalho, Oliveira e Lima (2018) por meio do trabalho da CPA torna-se possível um auto conhecimento da IES. Esta Comissão de avaliação interna pode desempenhar papeis cada vez mais relevantes, de modo a descobrir dificuldades antes que elas assumam tamanhos e proporções que se tornem mais difíceis de se governar. Neste ponto, considerou-se interessante apresentar a declaração de membro da CPA:

Nem sempre a Comissão Própria de Avaliação - CPA é lembrada e ficamos felizes em ter esta oportunidade de nos manifestarmos. Nós temos uma equipe de 6 participantes voluntários. Sendo uma comissão independente, por meio dela realizamos levantamentos periódicos em relação à satisfação dos envolvidos nos processos educacionais da faculdade em relação à infraestrutura, serviços e atendimento e à qualidade geral. Quando detectamos a insatisfação da turma 2017.1 principalmente do curso de Pedagogia, levamos o resultado à direção (reitoria, diretores e coordenadores) e agradecemos ao respaldo e atenção obtidos que levaram a reestruturar e melhorar a EAD na faculdade. Acreditamos que nossa missão foi cumprida, por meio do feedback que fornecemos à instituição e que possibilitou, como consequência, a realização seguinte dos trabalhos de pesquisa-ação. Mesmo sabendo que somos apenas uma parte pequena de uma grande 
Res., Soc. Dev. 2019; 8(8):e01881035

ISSN 2525-3409 | DOI: http://dx.doi.org/10.33448/rsd-v8i8.1035

engrenagem que é o sistema educacional da faculdade estamos felizes em saber que chegamos a um resultado feliz.

Os trabalhos envolvendo a questão da CPA são relativamente escassos no país. Como consideram Carvalho, Oliveira e Lima (2018), a CPA é importante para a auto-reflexão e melhoria da qualidade nas instituições de ensino superior. Apesar da importância mencionada, verifica-se que os levantamentos realizados por esta comissão nas IES em geral estão relacionados a melhorias de lanchonete, xerox, estacionamento, atendimento dos alunos etc.

Observa-se, por outro lado, que a evolução das Comissões de CPA nas IES, bem como sua maturidade, tem levado elas a atuar na melhoria das condições pedagógicas dos cursos superiores como se verifica no presente estudo.

O trabalho da CPA necessita da continuidade que são as ações da direção e coordenação com o emprego de metodologias como é o caso pesquisa-ação preconizadas por Thiollent (2011) e Ludke e Andre (2013) mencionados anteriormente e que podem levar a encontrar as solução e não ficar somente na questão de "apontar problemas".

Acreditamos que a educação brasileira está passando por um bom momento de evolução e desenvolvimento por meio do crescimento em quantidade de cursos e matriculas em cursos ou em disciplinas EAD e todo esforço no sentido de melhorá-la pode resultar em melhorias para a educação brasileira que poderá contar com profissionais melhor formados.

O presente artigo contribui com o saber sobre a educação a distância aplicada em cursos presenciais com até $40 \%$ de disciplinas ministradas na modalidade EAD. Ele mostra que as boas práticas podem apoiar o trabalho educativo, melhorando as condições dos processos de ensino e de aprendizagem e a satisfação dos alunos.

\section{Considerações finais.}

A história da EAD se iniciou na década de 30 como considera Zamlutti (2006) e essa continua sendo escrita nos dias atuais com os novos recursos que podem ajudar a melhorar a comunicação entre os atores bem como pelo uso das boas práticas que vão surgindo ao longo do tempo em uma história que está sendo escrita e que pode ajudar a melhorar a educação. 
Realizou-se um estudo de pesquisa-ação em uma turma de um curso de Pedagogia presencial em uma disciplina de Metodologia Científica ofertada na modalidade EAD. Como a faculdade não possui experiência em relação a esta modalidade educacional, em um primeiro momento, trabalhou da forma mais simples e com pouco investimento tanto na infraestrutura quanto no preparo da equipe multidisciplinar de professores e tutores e como resultado houve dificuldades de aprendizado.

Nos levantamentos realizados pela CPA detectou-se a insatisfação dos alunos. Em reunião posterior entre alunos e professores, houve a identificação dos motivos da insatisfação que era específico nas disciplinas EAD que não possuíam interatividade de modo a deixar os alunos confusos e sem interatividade.

Por meio do trabalho de pesquisa-ação realizado, houve uma reflexão e mudança na forma de trabalho bem como de investimento em estrutura e formação de tutores, seguindo as boas práticas de mercado.

As boas práticas na EAD consideram a necessidade de atuação do tutor no sentido de interagir com os alunos de forma afetiva, com dialogia e empatia. Há a necessidade de participação frequente do tutor com comentários e/ou respostas rápidas às participações dos discentes de modo que estes não se sentem isolados ou que ninguém está lendo suas postagens no AVA.

As alunas elogiaram as melhorias que surgiram a partir da CPA e a continuação dos trabalhos de pesquisa-ação que levaram a alcançar uma nova condição educacional na qual passou a existir uma tutoria ativa, interativa e participante, houve a introdução das resposta ou comentários da tutoria em até 24 horas após alguma postagem realizada por aluna e houve o incentivo para que todos participassem das ferramentas forenses, chats e outras atividades a distância.

O aprendizado ocorreu na turma seguinte de modo bem sucedido e isso levou a IES que trabalhava com $20 \%$ a considerar um novo momento partindo para trabalhar com $40 \%$ de EAD e também em se credenciar para a oferta de cursos na modalidade completamente a distância.

Sugere-se para trabalhos futuros que se realizem estudos com mais outros cursos em outras disciplinas na modalidade a distância de modo a se desenvolver bases de saber sobre as boas práticas na EAD. 


\section{Referências}

Basso, A. (2017). Avaliando em matemática através de rubricas. In: EDUCERE - XIII Congresso Nacional de Educação. IV Seminário Internacional de Representações Sociais, Subjetividade e Educação - SIRSSE e, VI Seminário Internacional pela Profissionalização Docente - (SIPD, Cátedra UNESCO). Formação de professores: contextos e sentidos práticos. Curitiba-PR 28 a 31 de agosto de 2017. Disponível em:

<http://educere.bruc.com.br/arquivo/pdf2017/24029_11960.pdf>. Acesso em: 20 maio 2019.

Biagiotti, L.C.M. (2005). Conhecendo e aplicando rubricas em avaliações. In: $12^{\circ}$ Congresso Internacional de Educação a Distância da ABED 2005. Florianópolis/SC. Disponível em: <http://www.abed.org.br/congresso2005/por/pdf/007tcf5.pdf>. Acesso em 21 maio 2019.

Boghi, C., Shitsuka, R., Shitsuka, D. M. (2019). Um estudo da possibilidade da minimização da evasão na educação a distância apoiada por terapia alternativa. Research, Society and Development. 8(1):1-15. DOI: http://dx.doi.org/10.33448/rsd-v8i1.567.

Brasil (2004). Lei n.10.861, de 14 de abril de 2004. Institui o Sistema Nacional de Avaliação da Educação Superior - SINAES e dá outras providências.

Brasil. (2012). Guia de boas práticas em contratação de soluções de tecnologia da informação. Publicado pelo Tribunal de Contas da União (TCU). TCU, Brasília.

Brasil. (2016). Portaria n. 1134, de 10 de outubro de 2016. Portaria dos $20 \%$.

Brasil. (2018). Portaria n. 1.428, de 28 de dezembro de 2018. Dispõe sobre a oferta, por Instituições de Educação Superior - IES, de disciplinas na modalidade a distância em cursos de graduação presencial.

Carvalho, H. A., Oliveira, O. S., Lima, I.A. (2018). Avaliação Institucional em uma universidade pública brasileira multicampus: processos e desafios na qualificação da gestão. Avaliação, Campinas; Sorocaba, SP, 23(1):217-243, mar. 2018. Disponível em: 
<http://www.scielo.br/pdf/aval/v23n1/1982-5765-aval-23-01-00217.pdf>. Acesso em: 20 maio 2019.

Ludke, M.; André, M. E. D. A. (2013). Pesquisas em educação: uma abordagem qualitativa. 2.ed. Ed. EPU, São Paulo/SP.

Mirshawka, V. \&; Mirshawka Jr., V. (2002). O boom da educação. DVS, São Paulo/SP.

Pereira, A.S.; Shitsuka, D.M.; Parreira, F.J. \& Shitsuka, R. (2018). Metodologia da pesquisa científica. [e-book]. Ed. UAB/NTE/UFSM, Santa Maria/RS.

Risemberg, R. I. C. S., Shitsuka, R., Tavares, O.L. (2015). Un Estudio de Caso de Reconocimiento de Patrones en los Textos Colectivos en el Ciberespacio Mediante la Herramienta Wiki en Cursos a Distancia de Pregrad. Dialogos de la Comunicacion. Felafacs. 91(2). Disponível em: <http://dialogosfelafacs.net/wpcontent/uploads/2015/09/Dialogos91_UN_ESTUDIO_DE_CASO_DE_RECONOCIMIENT O_DE_PATRONES_EN_LOS_TEXTOS-.pdfhttp://dialogosfelafacs.net/wpcontent/uploads/2015/09/Dialogos91_UN_ESTUDIO_DE_CASO_DE_RECONOCIMIENT O_DE_PATRONES_EN_LOS_TEXTOS-.pdf >. Acesso em: 21 maio 2019.

Severino, A. J. (2016). Metodologia do trabalho científico. 24ed. Ed. Cortez, S.Paulo/SP.

Shitsuka, R. \& Shitsuka, D.M. (2018). Formação de tutores para atuar na disciplina de LIBRAS em um curso de graduação a distância: um estudo de caso. Paidea - Revista Ciêntifica de Educação a Distancia. 10(17), jan. 2018. Disponível em:

$<$ http://periodicos.unimesvirtual.com.br/index.php?journal=paideia\&page=article \&op=view \& path[]=807\&path[]=714>. Acesso em: 21 maio 2019.

Silva, P. C. D., Shitsuka, R. \& Paschoal, P. A. G. (2014). Afetividade nas interações em AVA: um estudo sobre a interação na educação a distância. RBAAD da $A B E D, 14(1)$ :12-20. Disponível em:

<http://www.abed.org.br/revistacientifica/_Brazilian/2015/01_AFETIVIDADE_NAS_INTER ACOES.pdfhttp://www.abed.org.br/revistacientifica/_Brazilian/2015/01_AFETIVIDADE_N AS_INTERACOES.pdf >. Acesso em: 20 maio 2019. 
Tenório, A., Costa, M. F. A. C. \& Tenório, T. (2016). A influência da empatia como competência socioafetiva na atuação de tutores a distância. RBAAD da $A B E D, 15(1): 11-22$. Disponível em:

<http://www.abed.org.br/revistacientifica/_Brazilian/2016/01_Influencia_da_competencia.pdf http://www.abed.org.br/revistacientifica/_Brazilian/2016/01_Influencia_da_competencia.pdf >. Acesso em: 21 maio 2019.

Thiollent, M. (2011). Metodologia da pesquisa-ação. Ed. Cortez, São Paulo/SP.

Vergara, S. C. (2007). Estreitando relacionamentos na educação a distância. Cadernos EBAPE.BR, 5(spe), 01-08. https://dx.doi.org/10.1590/S1679-39512007000500010

Zamlutti, M. E. M. (2006). Uma análise do surgimento da educação a distância no contexto sóciopolítico brasileiro do final da década de 30 e início da década de 40. Tese (Doutorado) Universidade Estadual de Campinas - UNICAMP - Campinas, SP.

\section{Porcentagem de contribuição de cada autor no manuscrito}

Ricardo Shitsuka - 25\%

Dorlivete Moreira Shitsuka - 15\%

Maria Fani Scheibel - 15\%

Alaíde Japecanga Pereira - 15\%

Caleb David Willy Moreira Shitsuka - 15\%

Max Leandro de Araújo Brito - 15\% 